
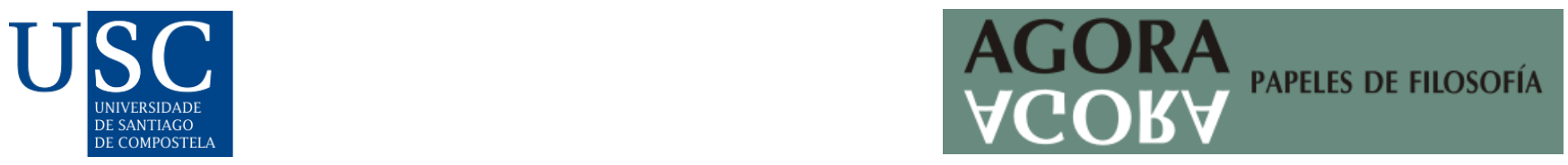

Agora. Papeles de Filosofía, 41(1), 2022. ISSN-e: 2174-3347

https://doi.org/10.15304/agora.41.1.7642

Recensiones

\title{
MARTÍN GÓMEZ, María: Diario de una filósofa embarazada, Tecnos, Madrid, 2021, 184p.
}

\author{
Martín González Fernández
}

Recibido: 15/04/2021; Aceptado: 21/04/2021

María Martín hace alusión, en su reciente libro, a Galicia: a la ría de Vigo (donde nació y, tal vez, fue gestada, nos queda por despejar esta incógnita), a la metáfora del camino (muy ligada a nuestra USC, a la hermenéutica y a su Facultad de Filosofía) y al poema Negra sombra de Rosalía de Castro (que encabeza el capítulo 16, y último, del libro). Sería ya ésta una buena razón para que mereciera la atención de los gallegos.

Pero esto es superficial y anecdótico, o no tanto, según se vea, comparado con la riqueza de fondo que nos trae su trabajo. Nosotros aquí, le llamamos «mareas vivas», porque tampoco evita la polémica. Todo en el texto es sencillamente bello. Incluso la portada de Joss Marino ha sido un acierto absoluto y debemos felicitarlo a él y a la propia editorial. Libros sobre "Filosofía y maternidad" hay algunos, ciertamente, incluso es tema que abordan con frecuencia y desde distintas perspectivas los movimientos feministas, y María no se olvida de ellos. Pero el planteamiento en sí del que tenemos entre manos es absolutamente original. Nos habla del misterio de la vida, que no es poco. En su sentido más amplio, y desde el enfoque fenomenológico de la Lieb, de la experiencia vivida, en su radical materialidad o corporeidad. Autoconciencia de un embarazo. Una fenomenología del espíritu encarnado. El universal concreto. Otros títulos hubiesen sido válidos. Me gustan dos: «Era martes y tenía yoga» (por su espontaneidad, más literario y acompañado como subtítulo el que actualmente lleva como título, y porque hace bajar la filosofía del cielo de las ideas a la tierra de una experiencia cotidiana, y compartible) y, mejor que mejor, el dicho de una de las matronas: «la gestación es un proceso, no una enfermedad» (más sólido conceptual y vivencialmente, desde el marco del frente de batalla, invocado en el cap. 14). Tú misma, querida María, invocas la figura de Heráclito de Éfeso, ya desde el inicio del trabajo. Y, en efecto, leído y releído el texto, sin duda, cabe colocarlo más en la estantería de la literatura épica, más digo, que en el de la de aventuras. Lo extraño, que no raro, es que siempre ha sido así. Lo cuentan nuestras madres. El desenlace de tus dos embarazos ha sido por suerte feliz, y todos nos alegramos de ello: Bruno y Cecilia, Cecilia y Bruno. Por desgracia no siempre acontece así. Un dato estadístico: durante la pandemia, en Galicia, se han dado muchos partos prematuros y con alta mortandad de neonatos. Incluso podría darte un dato de sororidad, o germanía, y duelo local: una pareja de tu misma edad, primerizos también, embriagados de ilusión, embarazo sin aparentes nubarrones en el horizonte, vecinos puerta con puerta nuestros, en una aldea de no más de 25 habitantes (la típica aldea gala de nuestra tierra), ha perdido a sus dos gemelos, Marco y Fabio, por parto prematuro (200 gramos el uno, apenas cabía en una mano, y 450 gramos el otro, apenas las dos manos le valían de improvisada 
cuna). Algo estamos haciendo mal los terrícolas para que el infierno se desate y multiplique por mil aquí.

Todos los capítulos son de interés: $1^{\circ}$ ) El origen; $2^{\circ}$ ) Tener o no tener, esa es la cuestión; $3^{\circ}$ ) Un acto de inmoralidad; 4을 Experimentar la gestación sin clichés; 5으 La vida, que sale al

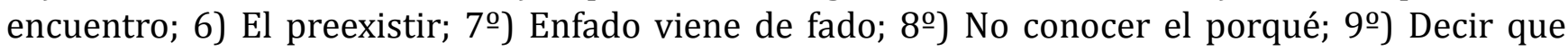

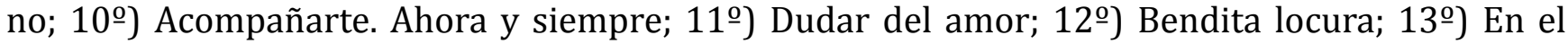

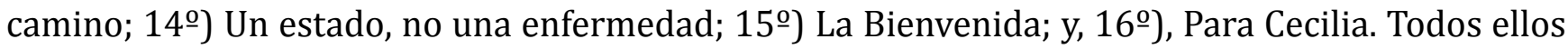
resultan atractivos en la fábrica literaria, y potentes como testimonio vital. Estamos en forma. Sin complacencias. Ni pedanterías siempre innecesarias, por más que evoquemos a los grandes en cada momento, ni gestos cursis. A la altura del oficio. Se mantiene la fuerza del valor testimonial. Un nuevo banquete o festín de ideas insólito para alguno de nosotros, incluso los del gremio. Pero tampoco creo que sea relato exclusivo para tu parroquia. Y a los hombres, no necesariamente a los machos, pero tampoco a los filósofos, nos viene bien un retrato así. No es un texto o manual de autoayuda, sino de pura y plena filosofía práctica, y por ello debemos felicitar a la autora. Como diría J. Ortega y Gasset, el capítulo más «batallón» es sin duda el Capítulo 3o, en donde pruebas con más eficacia y firmeza tus armas dialécticas. Te prevengo: generará polémica. Lo indicaba arriba. Pero eso es bueno para el libro y su propósito, y no hablo precisamente de números, ventas y rentas. Tengo que confesar que discrepo de tu criterio en este punto, personalmente, y sin ánimo de contradecirte, puesto que, en un mundo cargado de inmoralidades, la moral en sí misma se banaliza y casi es lujo. Diera la (falsa) impresión de que te muestras negacionista o qua-non (accidental) en tu crítica a los movimientos birth strike, por un lado, y, por otro, ante el antinatalista de David Banatar. Los que te conocemos sabemos que para nada esto es así. Y tú misma lo dejas entrever cuando te manifiestas activista del ecologismo, defensa de la Naturaleza, y del feminismo, o de lucha por causa de la mujer y sus derechos. Pero ninguna razón sobra. El diálogo debe prevalecer sobre cualquier radicalismo, sea del tipo que sea, pues toda ideología tiene un límite, es la primera verdad del filósofo. ¡Entrad, entrad, en el fuego moran los dioses!, les decía el Heráclito de Éfeso del naturalista Aristóteles a unos despistados que querían conocerle en persona y no se atrevían a dar un paso viendo la humilde choza en que vivía, sencillamente no le reconocían. Es una invitación a compartir lo que nos une.

Echo en falta un capítulo, cuyo corazón teórico se deja entrever sin embargo en un pasaje de J. Kristeva que incluyes, y que tiene dimensión, a la vez, ontológica y psicológica. Pues nos remite a la construcción de la identidad. Son asuntos, que no problemas aciagos y aún tristes, que ya en los años 60 de siglo pasado se planteaban los movimientos de la anti-psiquiatría y hoy los hacen los de la etno-psiquiatría. El desasosiego del principio de individuación. La experiencia de un cuerpo que se separa de una unidad de la que antes formaba parte, de otro cuerpo, el sentimiento de extrañeza del recién nacido, un proceso de desdoblamiento con el que tendrá que enfrentase el resto de sus días. De la placenta cálida heracliteana al desconocido mundo exterior (solutos ab). Pero entiendo también que - en esa mágico, y violento, momento de la escisión original-prima el silencio (muy relativo, claro está, en un paritorio: entre suspiros de alivio del dolor de la madre y primeros llantos, y no suaves precisamente, del bebé recién parido [en el lenguaje coloquial, entre la admiración por el milagro y el minimum físico del sujeto, se le suele llamar tan sólo «el recién», con cierto temor ancestral y teúrgico a que se rompa cuando se le nombra], por lo que yo recuerdo; casi llego tarde por enredarme torpemente con pijama de quirófano, gorros y patucos desechables, y mascarillas, y demás, hoy no me hubiese pillado por sorpresa, no, con la que tenemos encima todos), prima el silencio, digo, de la madre y del niño, la primera ha gestionado una vida, 
con todo tipo de experiencias, con todo tipo de incertezas, de retos, de angustias también, que para el bebé tan sólo acaba de empezar. (Recomiendo para un acercamiento al caso un capítulo, duro, de nuestro antropólogo de cabecera, ya jubilado, Gondar Potasany, Marcial: «Aposta por una filosofía non ensimismada» [ya desde el apartado: “Estructura de autoconsciencia e escisión”]: en Fidelidade a terra. Estudos dedicados ó profesor Xosé Luís Barreiro Barreiro. Santiago de Compostela: USC, 2011, con una pluma colaboradora amiga y muy querida aquí, el que sería futuro catedrático de Historia de Filosofía Española de la USAL, tu Universidad, D. Antonio Heredia Soriano). Pensándolo bien, tal vez ese capítulo estuviese de más.

Para ir terminando, diré algo que nuestro antropólogo dijo en aquel trabajo de nuestro hispanista, Catedrático de Filosofía Gallega, jubilado ya también, y gran especialista en el Romanticismo alemán: querida María, tú apuestas en filosofía por el «universal concreto» (Karel Kosik), al ponerla al servicio de la vida, de los problemas cotidianos, y que nos acucian. Nos decía David Hume, en su ensayo sobre el arte del ensayismo, nuestra disciplina no puede quedarse en la covacha del conventual ni en el trajín del periodismo fácil y alegre (raro entonces): debe llevar o elevar la preocupación común y popular o a ras de tierra al nivel de la reflexión articulada y conceptual. El intelectual es una suerte de embajador. Marcial Gondar Portasany celebraba el ejercicio intelectual del homenajeado por hacer de la filosofía la conciencia de una tierra, de una gente y de una cultura y lengua; para él sería un ejercicio de filosofía de compromiso, no ensimismada, «non ensimismada». Nuestro David Hume gallego (mejor debiéramos llamarle, por la orientación de la magnífica obra que nos ha legado, I. Kant gallego) nos lo explicaba incluso arguyendo razones prácticas y de supervivencia institucional (lo dejaré en gallego): «Non só por ser fieis á tradición é urxente apostar por una Filosofía que serva para a vida. Estamos nun momento histórico onde non hai xa mosteiros que subvencionen cos propios recursos aos seus traballadores da especulación, as universidades xa non dispoñen de rendas propias que as faga independentes da sociedade e aqueles postos de bibliotecas ou curadores de museos con que os políticos ilustrados axudaban económicamente aos savants necesitados, xa se xestionan con outros criterios. Hoxe os estudios de Filosofía e, por sabido, as Facultades universitarias ou son quen de convencer á sociedade e aos seus xestores de que son algo mais que un luxo prescendíbel ou será complicado poder sobrevivir desta maneira. / E isto, para nada ten que significar vender a autonomía do pensamento nin, menos, prostituilo ao servicio dos intereses alleos. Pódese e débese ser maximamente critico coa sociedades sen que isto queira dicir non estar ao servicio dela. Só una condición é precisa: facelo de tal xeito que a sociedade perciba que o que facemos ten sentido para eles $e$ [que] non pretendemos poñelos [a eles] ao noso servicio». Llevar la Filosofía a la plaza pública, al gran público, dialogar con los problemas y angustias de la gente de carne y hueso, intentar mostrar que, además de sus legítimos intereses particulares, «pode e debe cumprir a función de fecundar outros saberes nos que pode aportar perspectiva absolutamente innovadoras». Son cargas demasiado pesadas y sagradas, pero tu libro, María, a su escala, cumple con creces este dispositivo de criterios y retos.

Hace realmente pequeños los esfuerzos de otros. Yo mismo he estado trabajando, y algo tengo publicado ya, sobre una ontología matriarcal (mater / materia), ligada a la figura de Giordano Bruno de Nola, un «hombre libre», y comprometido con la crítica a la sociedad y filosofía de los tiempos pasados, como lo será sin duda tu Bruno, sin olvidar a Cecilia. Y, leyéndote, me siento un enano. Pero no aquellos enanos a hombros de gigantes de que hablara con tanta solemnidad Bernardo de Chartres y nos recordaba luego Juan de Salisbury. No, no, enano "simples", que dirían los hermanos portugueses. Por las razones indicadas más arriba, la editorial que ha publicado tu trabajo, la editorial Tecnos, merece también nuestra felicitación. Nuestra gratitud viene de atrás y se 
ha acrecentado con la reciente reedición de los diálogos en vulgar italiano escritos en la Inglaterra isabelina por, precisamente, Giordano Bruno. Es una material escolar y universitario excelente. Cualquier cosa que toque Miguel A. Granada Martínez lo es, y ya, en la recta final, esperemos que lo anime a publicar en su sello lo que resta del proyecto, incluido una nueva versión de Los Heroicos Furores, 60 de ellos, editado por Tecnos en 1987, con magnífica introducción, traducción y notas de Ma Rosario González Prada; pero del que todos añoramos, además, el complemento de una edición crítica al estilo de las que Granada, nuestro especialista internacional en Bruno y filosofía renacentista, nos tiene acostumbrados. Estamos convencidos de que la una no anula la otra. Y si ya pudiera arrancarle el compromiso de verter al español el magno poema De innumerabilibus, immenso, et infigurabili (1591), resultaría faena editorial completa. Cada quien y cada cual debe cumplir de la mejor manera su propio destino.

Sin embargo, tengo que decir, que otros deberes ya los tenía adelantados. No puedo ser mujer, claro. Es imposible imaginar siquiera a I. Kant embarazado. Tal vez a F. Nietzsche sí, por su sensibilidad y consciencia fisiológica, pero, tampoco sabemos cómo habría acabado la cosa, tal vez como el rosario de la aurora: ahí tienes el caso de Doris Lessing, que sacrificó finalmente a sus hijos, en beneficio de la vanidad de su carrera y creación literaria. Podría escribir fingiendo género, por ejemplo. Y no lo descarto en un futuro. Aunque tal vez, para ser creíble, deba optar por la fórmula de la novela. Pero, en cuanto al presente, en la escritura y en aulas, o en la calle, me he hecho la promesa, para mí sagrada, de evitar mientras mi conciencia me lo permita emplear frívolamente, a nivel de metáforas o de cualquier otro subterfugio, lenguaje relacionado con el cuerpo femenino, para mí sagrado: aborto, flujo menstrual o ciclos menstruales, menstruación, furor uterino, feto, trompas de Falopio, muerte fetal, violación, aborto (lo repito por su frecuencia de uso), preñar, nidación, fecundación in vitro, reproducción asistida, parto prematuro, paritorio, parir, salir de cuentas, útero materno, placenta, romper aguas, embrión, líquido amniótico, embarazar, desembarazo, gestación, cordón umbilical, alumbramiento, cuello uterino, cesárea, estrechez pélvica, crecimiento intrauterino, embarazo psicológico, etc. Tu libro ha reforzado esta urgencia mía, que no sé muy bien de donde sale, no desde luego de nuestra sociedad, de nuestra cultura, ni de nuestra propia lengua. Mis felicitaciones, y mejores deseos para Bruno y Cecilia. 